\title{
Operation Control of In Situ Combustion Based on the Material Balance Equation
}

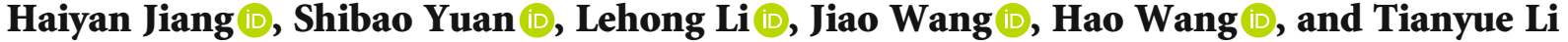 \\ College of Petroleum Engineering, Xi'an Shiyou University, Xi'an 710065, China \\ Correspondence should be addressed to Haiyan Jiang; upcjhy@126.com
}

Received 24 July 2020; Revised 11 September 2020; Accepted 12 October 2020; Published 1 December 2020

Academic Editor: Guanglong Sheng

Copyright ( 2020 Haiyan Jiang et al. This is an open access article distributed under the Creative Commons Attribution License, which permits unrestricted use, distribution, and reproduction in any medium, provided the original work is properly cited.

\begin{abstract}
The stability of combustion in the process of fire flooding requires not only a reasonable gas injection rate but also a matching exhaust rate. A reasonable injection-production balance system is very important. Based on the material balance of injectionproduction, the expression of injection-production ratio suitable for normal fire flooding production is established. The air injection rate of fire flooding combustion and oxygen consumption of formation pressurization is analyzed by this formula to calculate the gas production and liquid production in combustion. The reasonable injection and production parameters for the oilfield are calculated by using the oilfield parameters. It can be seen that the calculated value of injection-production ratio is consistent with the actual value, which shows that the injection-production ratio is reasonable and can guide the adjustment of production parameters in the oilfield.
\end{abstract}

\section{Introduction}

With the reduction of conventional oil resources, the proportion of low-efficiency reserves and low-grade reserves that are difficult to recover in old oilfields is increasing, and the exploitation of unconventional reservoirs is paid more and more attention in the current situation $[1,2]$. Heavy oil reservoir is more difficult to produce than conventional reservoir because of its high viscosity and poor fluidity. Fire flooding is an important development method of heavy oil thermal recovery; how to maintain the stability of combustion is very important for the recovery effect $[3,4]$. The design of air injection rate in the fire flooding is usually estimated according to the burning rate, well spacing, and burning scale [5-7]. From the point of view of combustion, a stable combustion needs not only a reasonable gas injection speed but also a matching exhaust speed. Otherwise, the combustion effect will inevitably be affected, and the development effect of fire flooding will be further affected [8-10]. Whether water injection development or air injection development of fire flooding, it is very important to maintain the balance of injection-production in oilfield development [11-14]. A reasonable injection-production balance system can not only meet the need of increasing the formation energy of liquid production but also can not cause the loss of crude oil and reduce the development effect [15-18].

The injection-production balance can be well designed by numerical simulation. As early as 1976, Chien and Shum did the first numerical simulation research in the fire flooding oilfield [19]. In 1979, Grabowski et al. proposed a fully implicit finite-difference thermal recovery model for fire flooding and steam flooding [20]. In 1989, Islam et al. compared and analyzed the previous numerical model of fire flooding and put forward a complete description model [21]. However, the model of numerical simulation technology is difficult to establish and requires many parameters, which is difficult to guide the adjustment of the parameters of the short-term development. In addition to numerical simulation, the design and analysis of the fire flooding mostly adopt empirical formula, with few parameters, easy to use but low accuracy.

The material balance of fire flooding means that under the reasonable injection-production parameters, the injected material and produced material can maintain the dynamic balance state and make the formation pressure rise steadily. Injection-production material is the basis of the system to 
maintain the dynamic balance. Considering the role of air in maintaining the combustion of crude oil and increasing formation pressure, the ratio of injected gas to produced gas is obtained in this paper by the principle of material balance, which provides the basis for the operation of fire flooding in the oilfield.

\section{Material Transfer in Fire Flooding Process}

Taking the gas injection wells, production wells, and reservoir as a unified system, the material transfer of the in situ combustion (ISC) process mainly includes the following parts.

\section{(1) Air injection}

The air is injected into reservoirs from the injector. Part of the air is used as an oxidant and combustion improver to participate in the combustion reaction in the underground, and others are used to increase formation pressure.

(2) The flue gas production by the burn of heavy components in crude oil

The composition of heavy component combustion products is very complex, such as hot water, steam, $\mathrm{CO}_{2}$, a small amount of $\mathrm{CO}$, and unreacted $\mathrm{O}_{2}$. The combustion reaction exists in the form of a combustion zone in the oil reservoir, which also is called the combustion front.

\section{(3) Production from producer}

The heat from combustion, hot water, and hot gas act on the crude oil in front, formed a series of complex oil displacement actions, such as viscosity reduction, expansion, distillation and vaporization, miscible driving, gas drive, and high temperature changing the relative permeability, which causes the fluid substance is produced from the reservoir.

According to the above analysis, the ISC process starts with air injection and ends with the mix produced. The transport process of various materials in the reservoir is as shown in Figure 1.

\section{The Balance of Injection-Production Process in Fire Flooding}

\subsection{Assumption}

(1) The reservoirs have been developed by steam stimulation, and there is a large amount of residual oil left in the reservoir. However, the declining of formation pressure is serious, and the formation pressure of the fire flooding process should be gradually recovered

(2) The gas injection wells of fire flooding adopt a row pattern, and the injector-productor ratio is $1: 1$

(3) The formation is in a stable combustion state, regardless of the combustion start-up and breakthrough stage

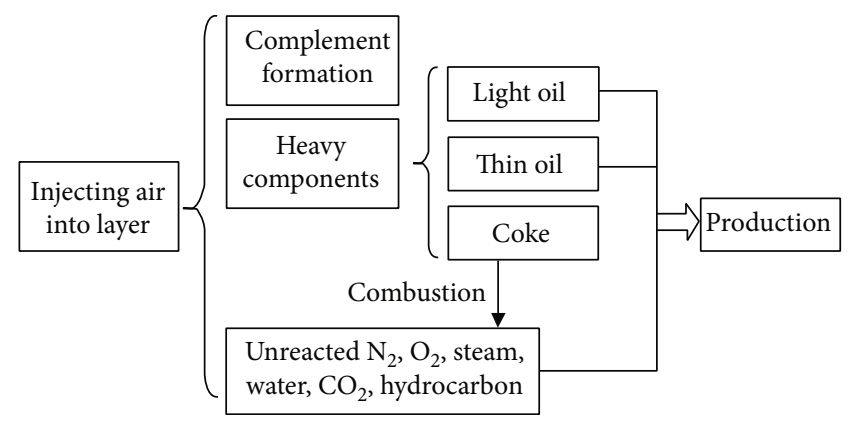

FIgURE 1: Material transport process in fire flooding.

3.2. The Calculation of the Amount of Air Injection in Stable Combustion. The air injected into the reservoir is used to (1) keep combustion, (2) flooding oil, (3) reservoir pressure build-up, and (4) not participate in the reaction and then be produced.

In the actual production, the amount of air that is not involved in the reaction is very small, so it cannot be considered in the calculation process.

3.3. The Air Required for Oil Combustion. In the actual production of the oilfield, the combustion products are mainly $\mathrm{CO}_{2}$ and water, and the proportion of $\mathrm{CO}$ is very small. In order to simplify the calculation process, the amount of $\mathrm{CO}$ is not considered. The high temperature oxidation reaction formula is simplified as formula (1):

$$
\mathrm{CH}_{x}+(1+0.25 X) \mathrm{O}_{2} \longrightarrow \mathrm{CO}_{2}+0.5 X \cdot \mathrm{H}_{2} \mathrm{O} \text {. }
$$

Formula (1) shows that $(1+0.25 X)$ mol oxygen can burn up $1 \mathrm{~mol} \mathrm{CHx}$ fuel, and the mass of $1 \mathrm{~mol} \mathrm{CHx}$ is $(12+X) \mathrm{g}$. When the fuel requite $m_{R}$ is known, the air requites for completely burning $1 \mathrm{~m}^{3}$ oil sand is as below:

$$
V_{R}=\frac{112.5 m_{R}}{12+X}(1+0.25 X) \frac{\mathrm{Nm}^{3}(\text { air })}{\mathrm{m}^{3}(\text { layer })},
$$

where $X$ is the apparent atomic $\mathrm{H} / \mathrm{C}$ ratio, which can be calculated by flue gas.

The air required for combustion is expressed as follows:

$$
V_{\text {air for combustion }}=V_{R} \cdot S \cdot v\left(\mathrm{Nm}^{3} / \mathrm{d}\right) \text {, }
$$

$v$-the velocity of the combustion front $(3.8 \sim 15.2 \mathrm{~cm} / \mathrm{d})$; $S$-cross-section area of combustion front, $\mathrm{m}^{2}$.

3.4. The Air Required for Oil Displacement. The drop of the formation pressure is mainly caused by the combustion of fuel, the production of oil, and water. The second role of air injection is to supplement formation pressure, and this part of air volume is called the air consumption of the displacement reservoir. In the reservoir conditions, the underground volume of this part of air is equal to the amount of the oil, water, and burned fuel produced every day.

The amount of liquid production is related to the capacity of the liquid supply of the formation. From the theoretical model of "one injector and one productor" and the liquid 
production formula, the expression of air consumption of displacement reservoir is shown in formula (4):

$$
V_{\text {driving }}=V_{\text {oil }}+V_{\text {water }}+V_{\text {fuel }}
$$

$V_{\text {driving }}$ - the air injection rate for displacement oil, $\mathrm{m}^{3} /$ day;

$V_{\text {oil }}$ - the oil rate, $\mathrm{m}^{3} /$ day;

$V_{\text {water }}$ - the water rate, $\mathrm{m}^{3} /$ day;

$V_{\text {fuel }}$-fuel consumption rate, $\mathrm{m}^{3} /$ day.

3.5. The Air Required for Increasing the Reservoir Pressure. The air injected into the formation can make up for the formation pressure loss caused by steam stimulation. In the whole process of fire flooding development, the formation pressure rises slowly with the development time. In the stable combustion stage, the pressure build-up curve can be approximately simplified to a linear one. The pressure rise rate called $\mathrm{Pv}(\mathrm{MPa} / \mathrm{a})$ is the slope of that line, and the average reservoir pressure after $n$ years is: $p_{r}=$ $p_{r 0}+n p_{v}(\mathrm{MPa})$.

In the $n$ year, based on Boyle's law:

$$
\left(p_{r 0}+n p_{v}\right)\left(V_{n}+\Delta V\right)=\left(p_{r 0}+n p_{v}+\frac{p_{v}}{365}\right) V_{n+1 / 365}
$$

$V_{n}, V_{n+1 / 365}$-gas volume in the reservoir of corresponding years, $\mathrm{m}^{3}$;

$\Delta V$-the amount of air injection for increasing the reservoir pressure, $\mathrm{m}^{3} / \mathrm{d}$;

$p_{r 0}$-initial average reservoir pressure, $\mathrm{MPa}$;

$n$-developing years minus one, which is $n$ years later.

The volume of the air injection has little change after the reaction; the pore volume in the reservoir can be approximately regarded as the volume of injected air. The volume of this part air is equal to the sum of the air requite for combustion and the air requite for oil displacement.

Formula (6) can be solved by formula (5):

$$
\Delta V=\frac{\left(p_{r o}+n p_{v}+p_{v} / 365\right) V_{n+1 / 365}}{p_{r o}+n p_{v}}-V_{n},
$$

$V_{n}$-the amount of air combustion and oil displacement at $n$ year, $\mathrm{m}^{3} / \mathrm{d}$.

3.6. The Total Air Injection Rate. In the process of combustion, tail gas produced by combustion and most of $\mathrm{N}_{2}$ are used to displace oil and supplement formation energy. Therefore, the total gas injection during fire flooding should be considered comprehensively. In general, the air-oil ratio in the initial stage of the fire flooding is very large, which is more than $3000 \mathrm{Nm}^{3} / \mathrm{m}^{3}$. In the stable period, the air-oil ratio will drop to $500-4000 \mathrm{Nm}^{3} / \mathrm{m}^{3}$. Air injection is sufficient to meet the needs of displacement and pressurization.

$$
G_{\text {air injection }}=V_{\text {air for combustion }} \text {. }
$$

When the reservoir pressure is in serious shortage and more air is needed to supply the pressure of the reservoir, the unreacted $\mathrm{N}_{2}$ and tail gas can continue driving oil and supplying the reservoir energy. The total air injection is as follows:

$$
\begin{aligned}
G_{\text {air injection }}= & \frac{0.05 X-0.1 m^{\prime}}{1+0.25 X-0.5 m^{\prime}} V_{\text {air for combustion }}+V_{\text {driving }} \\
& +\Delta V_{\text {increase the formation pressure }}
\end{aligned}
$$

\subsection{The Liquid and Gas Production of Fire Flooding}

3.7.1. The Liquid Production. Fire flooding development can be regarded as the injection of air from the injector to drive the formation fluid to flow from injector to productor. According to the relationship of reservoirs pressure recovering with time at the underground condition, the liquidproducing capacity in a certain time can be calculated as follows:

$$
N_{\text {liquid }}=\left(1+\frac{f_{w} \rho_{o}}{\left(1-f_{w}\right) \rho_{w} B_{o}}\right) \cdot V_{\text {oil }} \text {, }
$$

$\rho_{w} \cdot \rho_{o}$-density of water and oil, $\mathrm{g} / \mathrm{cm}^{3}$;

$f_{w}$-water cut, \%;

$B_{o}$-volume factor of crude oil;

$V_{\text {oil }}$ - the oil production rate, $\mathrm{m}^{3} / \mathrm{d}$.

3.7.2. The Gas Production. In the process of fire flooding, the gas produced from the productor mainly consists of steam, $\mathrm{N}_{2}, \mathrm{CO}_{2}, \mathrm{CO}$, hydrocarbon gas, and unreacted $\mathrm{O}_{2}$. The main components are $\mathrm{N}_{2}$ and $\mathrm{CO}_{2}$ when the fuel combustion is complete, accounting for more than $95 \%$ of the total. In the case of complete combustion, only the output of $\mathrm{N}_{2}$ and $\mathrm{CO}_{2}$ should be considered in the calculation of gas composition.

The consumption of fuel by combustion reaction is $1 \mathrm{~m}^{3}$ per day, so the volume of the gas production underground can be calculated as follows:

$$
\begin{aligned}
G_{\text {gas production }} & =\frac{34.822 Z R T V_{R} v S}{p}+\frac{9.375 Z R T V_{R} v S}{(1+0.25 X) p}, \\
G_{\text {gas production }} & =\frac{34.822 Z R T V_{R} v S}{p_{r 0}+n p_{v}}+\frac{9.375 Z R T V_{R} v S}{(1+0.25 X)\left(p_{r 0}+n p_{v}\right)},
\end{aligned}
$$

$S$-cross-section area of combustion front, $\mathrm{m}^{2}$;

$v$-the velocity of the combustion front, $\mathrm{m} / \mathrm{d}$;

$Z$ - gas compressibility factor, decimal number;

$R$-universal gas constant;

$T$-reservoir temperature, $\mathrm{K}$;

$\mathrm{P}$-average reservoir pressure, $\mathrm{MPa}$;

$N$-developing years minus one, which is $n$ years later.

3.8. The Injection-Production Ratio. The injection-production ratio (IPR) usually represents the material balance of injection-production in water flooding and reflects the relationship between water injection and fluid production. 
IPR is an extremely important parameter in the oilfield development process and is closely related to other parameters such as production rate and water cut. The reasonable control of IPR is an important task in the oilfield. According to the material balance, the reasonable IPR value is close to 1 .

The conventional water flooding IPR can be expressed as follows:

$$
\mathrm{IPR}=\frac{W_{i}}{N_{p} B_{o}+N_{p} \mathrm{WOR}} .
$$

In the fire flooding, the main injection gas is air, and the productions include oil, gas, and water. Therefore,
IPR can be expressed as follows:

$$
\mathrm{IPR}=\frac{G_{i}}{N_{p} B_{o}+N_{p} \mathrm{WOR}+G_{p}},
$$

IPR - injection-production ratio in fire flooding;

$W_{i}$-water injection;

$G_{i}$-air injection, $\mathrm{m}^{3} / \mathrm{d}$;

$N_{p}$-oil production, $\mathrm{m}^{3} / \mathrm{d}$;

$G_{p}$-gas production, $\mathrm{m}^{3} / \mathrm{d}$;

$B_{o}$ - volumetric coefficient of crude oil;

WOR-water and oil ratio.

According to the formula of the air injection rate, liquidproducing capacity, and gas production rate, the gas injection-production ratio is as below:

$$
\begin{aligned}
\mathrm{IPR}_{g}= & \left(G_{\text {air injection }}\right) /\left(G_{\text {gas production }}\right) \\
= & \left(( p _ { r 0 } + n p _ { v } + ( p _ { v } / 3 6 5 ) / p _ { r 0 } + n p _ { v } ) \left\{\left(1+\left(f_{w} \rho_{o} /\left(1-f_{w}\right) \rho_{w} B_{o}\right)\right)\left(2 \pi k h\left[p_{r 0}+p_{v}(n+1 / 365)-p_{w f}\right] P R / \mu_{o} \ln \left(R_{\mathrm{e}} / R_{w}\right)\right)\right.\right. \\
& \left.\left.\times 86.4 \times m-\left(1.89 X V_{R} v S /(1+0.25 X) V_{M} \rho_{w}\right) \times 10^{-3}+\left(m_{R} v S / \rho_{\text {coke }}\right)+\left(44.643 Z R T V_{R} v S /\left[p_{r 0}+p_{v}(n+1 / 365)\right] \times 10^{6}\right)\right\}\right) \\
& /\left(\left(34.822 Z R T V_{R} v S /\left(p_{r 0}+p_{v} n\right) \times 10^{6}\right)+\left(9.375 Z R T V_{R} v S /(1+0.25 X)\left(\left(p_{r 0}+p_{v} n\right) \times 10^{6}\right)\right)\right),
\end{aligned}
$$

$\mathrm{IPR}_{g}$ - gas injection-production ratio in fire flooding;

$p_{v}$ - the rate of formation pressure recovery $\mathrm{MPa} / \mathrm{y}$;

$m$-production-injection rate in fire flooding;

$S$ - the cross-section area of combustion surface;

$V_{M}$-molar volume of gases, $22.4 \times 10^{-3} \mathrm{~m}^{3} / \mathrm{mol}$;

$p_{w f}$-bottom-hole pressure;

$k$-permeability, $\mu \mathrm{m}^{2}$;

$h$-thickness of oil layer, $\mathrm{m}$;

$\rho_{w}, \rho_{o}$-water density and oil density, $\mathrm{g} / \mathrm{cm}^{3}$;

$\rho_{\text {coke }}$-fuel density, $\mathrm{kg} / \mathrm{m}^{3}$;

$\mathrm{PR}$ - productivity ratio;

$\mu$-viscosity of underground crude oil, $\mathrm{mPa} \bullet$;

$R_{e}, R_{w}$-well diameter, supply radius, $\mathrm{m}$.

Formula (13) is suitable for a stable combustion period in the development of conventional dry combustion, and the oxygen content is less than $1 \%$ in flue gas, which is hightemperature oxidation (HTO) mode in the reservoir.

The reasonable ranges of injection-production ratio, air injection, and gas production can be reached through the above formula (13). And different parameters in oilfield production can be modified by means of the theoretical data to make the combustion process work stable and effective.

\section{The Application of Material Balance Equation in an Oilfield}

4.1. The Introduction of Reservoir G3. The reservoir G3, which is located in Bohai Bay Basin in China, is a heavy oil reservoir. The producer-injector ratio is $21: 8$ in fire flooding pilot G3. The G3 block was put into development in 1987. After two stages of conventional exploitation and steam stimulation, the recovery percent of the block reached $16.45 \%$ at the end of 2007, and the formation pressure is only $2 \mathrm{MPa}$. The water sensitivity of the reservoir is changed from medium to strong, and the underground water storage is large. The heat loss is large, and the heat utilization rate is low, when hot water flooding and steam flooding are used. Therefore, fire flooding is adopted to replace development.

The wellhead gas injection pressure is $1.7 \sim 5.2 \mathrm{MPa}$ at the beginning of fire flooding and decreases to 1.5 3.2 $\mathrm{MPa}$ after half a year. With the extension of gas injection time and the increase of cumulative gas injection volume, the injection pressure began to rise slowly. At present, the injection pressure is $3.4 \sim 4.7 \mathrm{MPa}$ and shows an upward trend. In the gas produced from production wells and observation wells, the content of $\mathrm{O}_{2}$ is very low, which is $0 \%$ when the combustion is good. The highest content of $\mathrm{CO}_{2}$ is $25 \%$, generally $10 \%$ to $20 \%$, and the CO content is generally $1 \%$ to $2 \%$. At present, 13 ignition well groups have been formed in the fire flooding development of the block, with a daily oil increase of $51.9 \mathrm{t}$ and an annual oil increase of $1.89 \times 104 \mathrm{t}$. The basic data is shown in Table 1.

Taking $n=5$ as an example, in the sixth year of the development, the gas IPR is 1.12 when the velocity of the combustion front is $8 \mathrm{~cm} / \mathrm{d}$.

\subsection{Sensitivity Analysis of ISC Parameters}

4.2.1. The Effects of Vertical Sweep Efficiency and the Combustion Front Width. The average combustion front 
TABLE 1: Basic data of reservoir G3.

\begin{tabular}{|c|c|c|c|}
\hline \multicolumn{2}{|l|}{ Reservoir parameters } & \multicolumn{2}{|l|}{ Fluid parameters } \\
\hline Permeability, $\times 10^{-3} \mu \mathrm{m}^{2}$ & 6113 & Oil viscosity underground, $\mathrm{mPa} \bullet \mathrm{s}$ & 605 \\
\hline Water cut, \% & 60 & Volume factor & 1.042 \\
\hline Initial average reservoir pressure, $\mathrm{MPa}$ & 3.5 & Surface density of oil, $\mathrm{g} / \mathrm{cm}^{3}$ & 0.9420 \\
\hline Approximate bottom hole flowing pressure, $\mathrm{MPa}$ & 2.5 & Critical temperature of air, $\mathrm{K}$ & 140.7 \\
\hline Effective thickness, $\mathrm{m}$ & 62.7 & Critical pressure of air, $\mathrm{MPa}$ & 3.72 \\
\hline Rate of pressure recovery, $\mathrm{MPa} / \mathrm{a}$ & 0.12 & Productivity ratio & 0.8 \\
\hline Supply radius, $\mathrm{m}$ & 105 & Average combustion front width, $\mathrm{m}$ & 30 \\
\hline
\end{tabular}

The consumption of fuel $M_{r}=22.07 \mathrm{~kg} / \mathrm{m}^{3}$ is calculated by oil density in reservoir G3. So when the fuel is $M_{r}$, the air consumption for complete combustion $1 \mathrm{~m}^{3}$ (every cubic meter fuel) oil sand is as $V_{R}=266.02 \mathrm{Nm}^{3} / \mathrm{m}^{3}$.

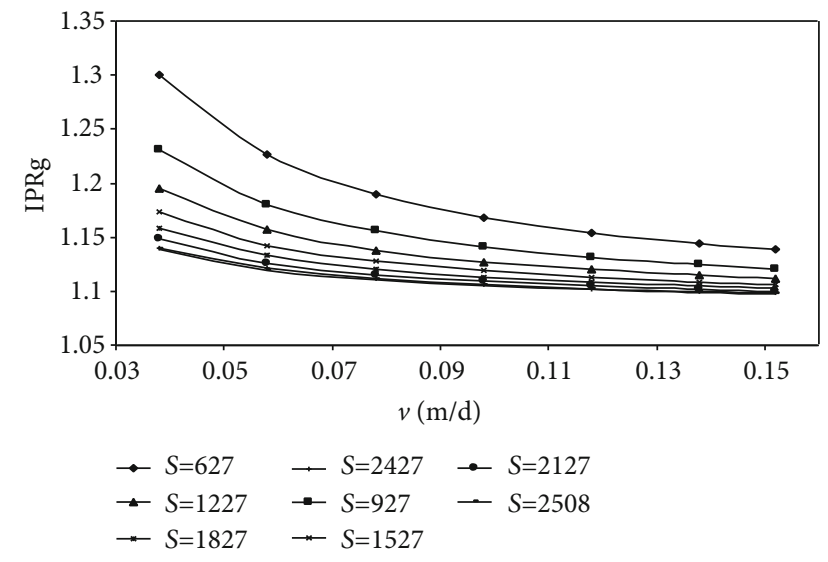

FIGURE 2: The relationship between the gas IPR and the velocity of the combustion front under different cross-section areas of combustion.

width in reservoir G3 is $30 \mathrm{~m}$ and the variation range of actual width is $20-40 \mathrm{~m}$. The formation thickness is $62.7 \mathrm{~m}$. The range of vertical sweep thickness is $31.35-62.7 \mathrm{~m}$, and the vertical sweep efficiency is $0.5-1$. The variation range of the cross-section area of the combustion front is 627$2508 \mathrm{~m}^{2}$. The relationship between the gas IPR and the velocity of the combustion front under different cross-section areas is shown in Figure 2.

Figure 2 shows that the gas IPR continues to decrease with the increase of the cross-section area of the combustion surface. At the same time, the velocity of the combustion front has less effect on gas IPR, so the combustion becomes more stable. The bigger of the vertical sweep efficiency is, the more stable the injection-production ratio will be. In the field production, the vertical sweep efficiency of fire flooding has a great relationship with development engineering factors. Reasonable well section position of perforation and longer perforation distance can effectively reduce the influence of reservoir heterogeneity on sweep efficiency, expand the sweep range of combustion front, and make gas IPR tend to be small and stable.

4.2.2. The Effects of the Build-Up of the Reservoir Pressure. The liquid production rate, gas injection, and production are affected by reservoir pressure. While the first, sixth, and

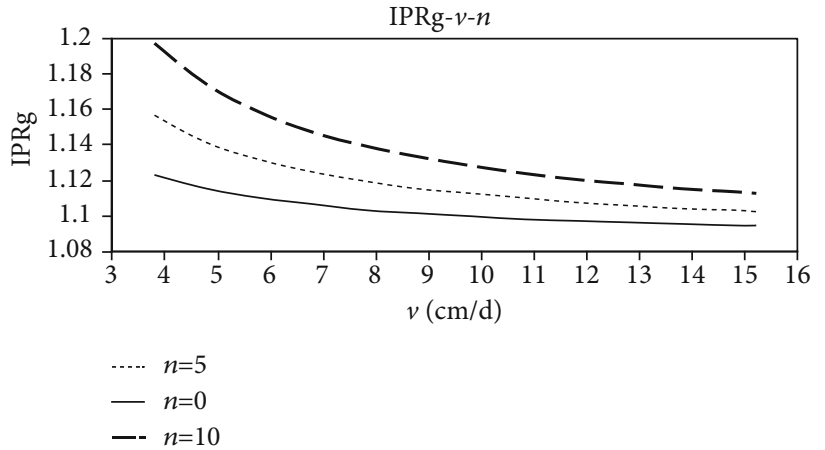

FIGURE 3: The relationship between gas IPR with the velocity of the combustion front at different time.

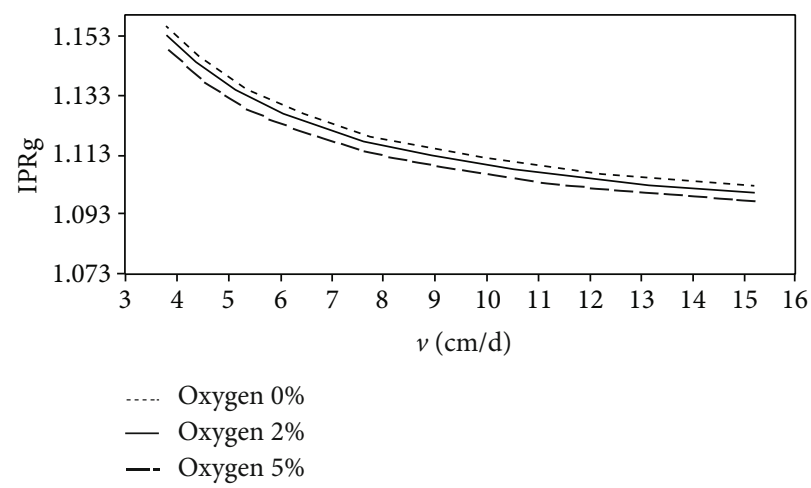

FIgURE 4: The effect of oxygen utilization on gas injectionproduction ratio.

eleventh year in the fire flooding process, the relationship between the gas IPR and velocity of combustion front is shown in Figure 3.

In general, with the increase of development time, formation pressure will be build-up and the liquid production rate will increase. Figure 3 shows that with the increase of development time, the gas IPR increases, and the numerical range of gas IPR increases gradually.

4.2.3. The Effects of Oxygen Utilization. If the flue gas contains a higher proportion of oxygen, the combustion reaction will change to low-temperature oxidation (LTO) mode, and some of the air mixtures flow through the formation without participating in any chemical reaction. Therefore, this partial 
gas can be added to the numerator and denominator of the IPR formula for the analysis. When the oxygen content is $0 \%, 2 \%$, and $5 \%$ in flue gas, the effect of oxygen utilization on gas IPR is as shown in Figure 4.

As shown in Figure 4, incomplete combustion will cause IPR decline, but the range of theoretical value is less affected. Actually, the change of IPR is the result of the multiple parameters in oilfield production. In order to make the IPR fluctuate within a larger range, it is necessary to analyze the geological parameters, the perforation, and the fluid properties in that reservoir, and use the IPR formula to optimize the fire flooding process.

\section{Conclusions}

(1) With the increase of the cross-section area of the combustion surface, the gas IPR becomes steady. Increasing the length of the perforation and optimizing the well section position of perforation can improve vertical sweep efficiency in the injection well, thus keeping the cross-section area of combustion surface in high level, and decrease the diversity of the combustion front

(2) Since the IPR formula created on the water cut is known, the water cut is a variable during the fire flooding process. In addition, the oxygen utilization has a great influence on IPR; both parameters must be monitored in real-time

\section{Data Availability}

The data used to support the findings of this study are available from the corresponding author upon request.

\section{Conflicts of Interest}

The authors declare that there is no conflict of interest regarding the publication of this paper.

\section{Acknowledgments}

The authors would like to thank the project supported by the National Natural Science Foundation of China (Grant No. 51674198), investigations on fuel transformation and deposition mechanism in the process of in situ combustion.

\section{References}

[1] G. Sheng, Y. Su, and W. Wang, "A new fractal approach for describing induced-fracture porosity/permeability/ compressibility in stimulated unconventional reservoirs," Journal of Petroleum Science and Engineering, vol. 179, pp. 855-866, 2019.

[2] G. L. Sheng, H. Zhao, Y. L. Su et al., "An analytical model to couple gas storage and transport capacity in organic matter with noncircular pores," Fuel, vol. 268, pp. 117-288, 2020.

[3] X. A. Zhang, Q. W. Liu, Z. Z. Fan, and Q. C. Liu, "An in situ combustion process for recovering heavy oil using scaled physical model," Journal of Petroleum Exploration and Production Technology, vol. 9, no. 4, pp. 1-8, 2019.
[4] S. Yuan, H. Jiang, Y. Shi, Z. Ren, J. Wang, and Y. Zhang, "Study on heavy oil components transformation path based on core analysis during in-situ combustion process," Fuel, vol. 253, pp. 72-78, 2019.

[5] P. S. Sarathi, In-Situ Combustion Handbook - Principles and Practices, Office of Scientific \& Technical Information Technical Reports, 1999.

[6] A. L. Benham and F. H. Poettman, "The thermal recovery process-an analysis of laboratory combustion data," Journal of Petroleum Technology, vol. 10, no. 9, pp. 83-85, 2013.

[7] B. B. Mandelbrot and J. R. Wallis, "Some long-run properties of geo-physical records," Water Resource Research, vol. 5, no. 2, pp. 321-340, 1969.

[8] D. J. Miao, Y. Zhang, G. Y. Li, and Q. J. Yang, "Research of injection-production voidage balancing system in water flooding reservoir," Drilling \& Production Technology, vol. 3, 2002.

[9] S. Yuan, H. Jiang, X. Li, X. Zhong, and K. Wang, "New method to determine position of combustion front for in-situ combustion in the multiple well groups," Petroleum Geology and Recovery Efficiency, vol. 21, no. 3, pp. 52-54, 2014.

[10] K. Mrldul and A. M. Garon, "An experimental investigation of the fire flooding combustion zone," SPE Reservoir Engineering, vol. 6, no. 1, 1991.

[11] C. Y. Lin, W. H. Chen, and W. E. Culham, "New kinetic models for thermal cracking of crude oils in in-situ combustion processes," SPE Reservoir Engineering, vol. 2, no. 1, 1987.

[12] H. Y. Jiang, S. B. Yuan, K. Ning, X. Y. Sun, H. X. Li, and J. J. Sun, "Singular perturbation approach analysis of fronts propagation of in-situ combustion," Journal of System Simulation, vol. 21, no. 22, pp. 7026-7032, 2009.

[13] K. M. Xu, Basic Research and Application of In-Situ Combustion Technology of Oil Production, Northeast Petroleum University, 2012.

[14] K. Ning, S. B. Yuan, and H. Y. Jiang, In-Situ Combustion Theory \& Practice, China University Of Petroleum Press, 2010.

[15] F. L. Zhang, Q. C. Liu, Q. H. Zhao, Y. Zhao, and H. Q. Cheng, "Study on mathematical models of the reaction of in-situ combustion," Special Oil and Gas Reservoirs, vol. 19, no. 5, pp. 5559, 2012.

[16] Y. H. Wang, Y. P. Chen, and S. C. Li, "Experiment study on oil driving by in-situ combustion," Petroleum Exploration and Development, vol. 27, no. 1, pp. 92-94, 2000.

[17] J. H. Zhang, S. H. Yang, and Q. L. Wang, In-Situ Combustion Production, Petroleum Industry Press Oil, 2000.

[18] J. A. Langhoff and C. H. Wu, "Calculation of high-temperature crude-oil/water/vapor separations using simulated distillation data," SPE Reservoir Engineering, vol. 1, no. 5, pp. 483-489, 2013.

[19] S. F. Chien and Y. M. Shum, Numerical Simulation of Temperature Profiles and Oil Production during Dry or Wet In -Situ Combustion for an Inverted 5-Spot Pattern, Society of Petroleum Engineers of Alme, 1976.

[20] J. W. Grabowski, P. K. Vinsome, R. C. Lin, G. A. Behie, and B. Rubin, A Fully Implicit General Purpose Finite-Difference Thermal Model for In Situ Combustion and Steam, SPE Annual Technical Conference and Exhibition, 1979.

[21] M. R. Islam, A. Chakma, and S. M. Ail, State-of-the-Art of InSitu Combustion Modeling and Operations, SPE California Regional Meeting, 1989. 